\title{
MOBILISING FAITH-BASED ORGANISATIONS FOR SOCIAL DEVELOPMENT THROUGH A PARTICIPATORY ACTION RESEARCH (PAR) PROCESS ${ }^{1}$
}

\section{Swart}

\section{INTRODUCTION ${ }^{2}$}

Established within the Faculty of Theology at the University of Stellenbosch in 2001, the Unit for Religion and Development Research (URDR) ${ }^{3}$ has embarked on a major initiative to research the social development needs of local communities and empower the faith-based organisations (FBOs) - churches and faith-based NGOs - in those communities towards self-reliant sustainable social development activity and outcomes (URDR web page). In particular, the work of the Unit proceeds from the understanding that resolving the majority of problems related to poverty in South Africa lies in carrying out two steps. The first is that one needs to gather data on the problem, and the problem must have a human face. The second step is networking, empowering and motivating all relevant parties in a society to address the problem. This problem can be solved only with strong input from grassroots level, where local communities are part and parcel of a participatory action process (Hendriks, Erasmus \& Mans, 2004:381).

Proceeding from such a basic aim and understanding of its work, the Unit upholds the hypothesis that the religious sector in South Africa, through its various FBOs, could play a significant role in fostering collective social development activity at the community level. In South Africa, URDR researchers argue, the Christian churches could well claim to be the country's strongest and most widespread non-governmental organisation (NGO). According to the World Values Survey, the church reaches on average $63 \%$ of the Christian population on a weekly basis (World Values Survey, 2000; Hendriks \& Erasmus, 2003). Moreover, over three quarters of the population have indicated that they are affiliated with the Christian religion (79.8\% - Census, 2001) and 82\% with religion in general (Census, 1996; Hendriks et al., 2004; Hendriks \& Erasmus, 2003). There are approximately 43000 Christian faith communities in South Africa (Froise \& Hendriks, 1999:37) and the infrastructure of FBOs reaches every corner of the country. Their leadership and human and organisational resources are also far-reaching. Congregations and other FBOs are value-based institutions with an effective infrastructure (Hendriks et al., 2004:382). Their potential to reach people, especially at the grassroots level, and act as catalysts of self-reliant social development initiatives could therefore be regarded as considerable.

Finally, the Unit is also strongly motivated by the government's increasing acknowledgement that it cannot on its own achieve its goal of creating a self-reliant society, and that it requires partners to deliver social development outcomes. The government's interest in the religious sector as a nongovernmental development organisation (NGDO) is based on this sector's organisational

\footnotetext{
${ }^{1}$ Paper prepared for presentation at the $19^{\text {th }}$ World Congress of the International Association for the History of Religions (IAHR) in Tokyo, Japan, 24-30 March 2005.

${ }^{2}$ This material is based upon work supported by the National Research Foundation of South Africa under Grant number 2054070. Any opinion, findings and conclusions or recommendations expressed in this material are those of the author and therefore the NRF does not accept any liability in regard thereto.

${ }^{3}$ Initially known as the Unit for Religious Demographic Research, the Unit's name was changed to the Unit for Religion and Development Research in 2003.
} 
infrastructure, its human resources and its credibility amongst people (Hendriks et al., 2004:382; Koegelenberg, 2001; Louw \& Koegelenberg, 2003). This interest was reiterated most recently at a consultation on state-religious sector development cooperation in Cape Town held on the $29^{\text {th }}$ of July 2004. In his address to some of South Africa's most prominent religious leaders, the Minister of Social Development, Dr Zola Skweyiza, committed himself to closer cooperation between government and the religious sector in tackling the issues of poverty, unemployment, HIV/AIDS and social security (Ministry of Social Development, 2004a). In particular, it was recognised by the minister that the religious sector could make a special contribution on the basis of its close proximity to the people on the ground. FBOs could play an invaluable role in ensuring effective social service delivery and in promoting the social values required to achieve new levels of social cohesion and cooperation in society. Most importantly, FBOs could serve as people's organisations that would mediate local people's authentic participation in development (Ministry of Social Development, 2004b).

This article gives a critical account, against the above background, of the participatory action research (PAR) process by which the URDR has aimed to achieve its goals of empowerment and self-reliant sustainable social development action and outcomes through the faith-based sector in selected communities in the Western Cape. As the stated objective suggests, the impression will not be created that the URDR initiative is without certain shortcomings. Neither will it be suggested that the URDR-initiated process has in actual fact succeeded in achieving far-reaching empowerment and self-reliant social development action.

Yet, what follows in this article is the description of a research initiative that the researchers in the URDR believe newly illustrates the role that institutionalised theological and religious research in the country could play, given its considerable resource and skills base, in enabling the kind of processes and outcomes whereby the faith-based sector in particular could begin to realise its acknowledged potential in the social development sphere. Starting off in critical fashion by pointing out that the URDR's PAR initiative ought to be viewed as a process of continuing adjustment and learning also on the part of URDR researchers themselves, several elements that have been applied throughout the research are also discussed. On the basis of this discussion and the critical view already presented, the article closes by giving further consideration to the ongoing challenge of conscientisation and empowerment in the URDR's endeavour to bring about an effective PAR process.

In the subsequent sections the discussion draws selectively on three sources of material: (i) documentation and results that were a specific outcome of the research conducted in 'first-round' initiatives in the town regions of Paarl and George, as well as in the follow-up initiative in the municipal area of Paarl/Wellington that was part of a larger initiative to replicate the URDR methodology throughout the greater Cape Town area (URDR web page); (ii) theoretical literature on PAR, in particular recent South African contributions to the field; and (iii) literature from the social development field that further enhances the critical perspective of the article.

\section{EMPHASIS ON PROCESS}

In the URDR a sense of modesty prevails regarding its initiative towards implementing a PAR process to date. This sense of modesty is highlighted by the critical nature of the literature on PAR, which highlights the 'tension' (Rahman, 1993:87) within PAR thinking regarding the role of the outside 'change agent' in the research process.

Located within a larger institutional environment that historically has emulated the Northern (or Western) academic and theological tradition (Erasmus, Hendriks \& Mans, 2004:3-4) and for 
political and ideological reasons has isolated itself from the larger community ${ }^{4}$, the URDR recognises that it may be premature at this stage of its strategic intervention to be regarded as an exponent of the more radical 'Southern' tradition (or school) in the PAR movement. On the contrary, the Unit acknowledges the fact that it should at present more realistically be defined as an exponent of the 'Northern' PAR tradition, which to a lesser extent than its Southern counterpart has been problematising the ideological and epistemological disposition of the outside 'change agents' and the organisations and their membership drawn into the research (Babbie \& Mouton, 2001:60-61; Prozesky \& Mouton, 2001:538-539).

In accordance with such a critical distinction, the URDR further acknowledges that it may not have brought as sharply into focus as in the 'Southern' tradition the role of the poor, oppressed and exploited in the research process (Rahman, 1993). Consequently, researchers in the URDR are sensitive to the fact that in terms of 'Southern' characteristics, their own initiative to date may not have been political at all; that it may not have posed an explicit challenge to the ideological, epistemological and power interests subjacent to the respective communities (Babbie \& Mouton, 2001:58-59, 62, 322-323, 330-331; Prozesky \& Mouton, 2001:540-541); that it may not have sufficiently drawn into the process the poor and exploited as the actual drivers (or mobilisers) of the process (Babbie \& Mouton, 2001:321-323; Prozesky \& Mouton, 2001:541-542, 546-547; Rahman, 1993:82-86, 88-93); that it has not led to any action strategies that have dealt effectively with the social problems in the communities (Babbie \& Mouton, 2001:320-322; Prozesky \& Mouton, 2001:546-547).

It is on the basis of such a self-understanding that the notion of process is emphasised right from the outset in the description of the URDR's PAR initiative. Thus the limitations of the current initiative are recognised. Therefore, in accordance with the principle of 'learning', which is identified as a primary goal in PAR, researchers in the URDR understand PAR to be a 'two-way educational process' whereby 'the change agent must also undergo a learning process' (Babbie \& Mouton, 2001:324; Prozesky \& Mouton, 2001:548). Through such an educational process, which implies an ongoing exposure to the personal experiences of the poor in the communities and the problems they face, they anticipate growing in critical understanding of the deficiencies of their present ideological orientation and intervention.

\section{PARTICIPATION AS FUNDAMENTAL PRINCIPLE}

For URDR researchers, however, the research process has gained legitimacy through the way in which their research engagement has been founded on the principle or notion of participation (Erasmus, Hendriks \& Mans, 2005:2-3; 2004:3-4). In the light of the above-mentioned NorthSouth distinction, the URDR takes comfort in the recently developed South African perspective that 'participation' could be regarded as the one common element that defines both the 'Northern' and 'Southern' traditions as manifestations of the PAR methodological approach. In terms of the

${ }^{4}$ The URDR is a research centre of the University of Stellenbosch and its Faculty of Theology, which historically are both rooted in the tradition of North European scholarship and continue to have strong links with that tradition. In addition, the history of the University and Faculty as institutions influenced and shaped by apartheid ideology and politics is also well known. Whilst both have in recent years embarked on a laborious process to change their past identity and transform themselves into democratic and socially conscious institutions, the process is still far from concluded. For a more detailed impression, see the various speeches of the Rector since 2002 (http://sun.ac.za/university/management/rector/speeches.html) and documentation on the university's 'Community Interaction Policy and Plan' published on the web site of the university (http://admin.sun.ac.za/coraffairs/community/nuus.html). 
following definition, which the South African perspective proposes as basic to both traditions of PAR:

"Participatory action research involves some members of the subjects of study participating actively in all phases of the process from the design of the project, through its implementation, and including the actions that come with or follow upon the research." (Whyte in Babbie \& Mouton, 2001:61; Prozesky \& Mouton, 2001:539)

Thus researchers in the Unit have likewise claimed to have adopted a methodology by which the 'locus of control' has shifted 'away from the specialist researcher to the local community and the participation of people from the community' (Erasmus et al., 2004:3). Yet, this shift could be described as having at first been a rather intuitive move within the URDR towards a PAR mode of engagement, based on the alternative scientific understanding that research about poverty would be meaningless without people's direct involvement in the process:

"We wanted to know in what ways the local community could participate in the project and specifically in ways that would preserve the integrity of their contribution. We realised that the sustainability of the project would depend on the participation of all role players in both the planning and execution of the project. Thus the methodology had to contribute to a process in which the research forms part of the mobilising of the community for change. The research had to empower those involved to transform their communities with this newly acquired information... This way of thinking brought us to the research paradigm of Participatory Action Research (PAR).” (Erasmus et al., 2004:3; Erasmus et al., 2005:2-3).

In terms of the PAR 'scale' of participation, it could be asserted by URDR researchers that a rather advanced degree of participation has been achieved. It has been a mode of engagement that has not been interested merely in consulting members of the community about aspects of the research. Along the continuum of progressive PAR research, the URDR initiative has deliberately aimed to go a step further by engaging the communities as co-designers and -executors of the research. On the basis of the research results, it has set an open agenda for the future whereby the communities could take responsibility for and decide on the appropriate courses of action to address their social problems (Babbie \& Mouton, 2001:316-317; Prozesky \& Mouton, 2001:543).

\section{MOBILISATION THROUGH RELIGIOUS VOLUNTEERS}

It is important to emphasise the role that volunteers from local FBOs - in particular churches have played as catalysts and actual executors of the PAR process. As a centre of research primarily interested in exploring and strengthening the nexus between religion and development on a conceptual and strategic level (Erasmus et al., 2005:3), the URDR would necessarily seek to find its point of contact in the faith-based sector of the respective communities to initiate the PAR process.

What has followed is a process by which local FBOs - congregations and NGOs - have not only served as the meeting points for sharing the vision of PAR with members of the communities and their leadership. Ordinary members from this sector also engaged on a voluntary basis in the planning of the PAR initiatives and acted as the agents of the multifaceted methodology described in the next section (Erasmus et al., 2005:3-7; 2004:5-10; URDR, 2004:7-9; 2003:10-14).

One may summarise the point by saying that members from the faith-based sector in particular have been instrumental in mobilising a broader group of people in their communities to participate in a 'first round' of PAR and voice their experiences and insights about local problems through questionnaire survey and needs analyses. Moreover, this information has been used by the URDR 
in ongoing consciousness-raising events (Babbie \& Mouton, 2001:322; Prozesky \& Mouton, 2001:547-548) to mobilise local FBOs and their communities at large for appropriate action.

\section{APPLICATION OF A MULTIFACETED RESEARCH METHODOLOGY}

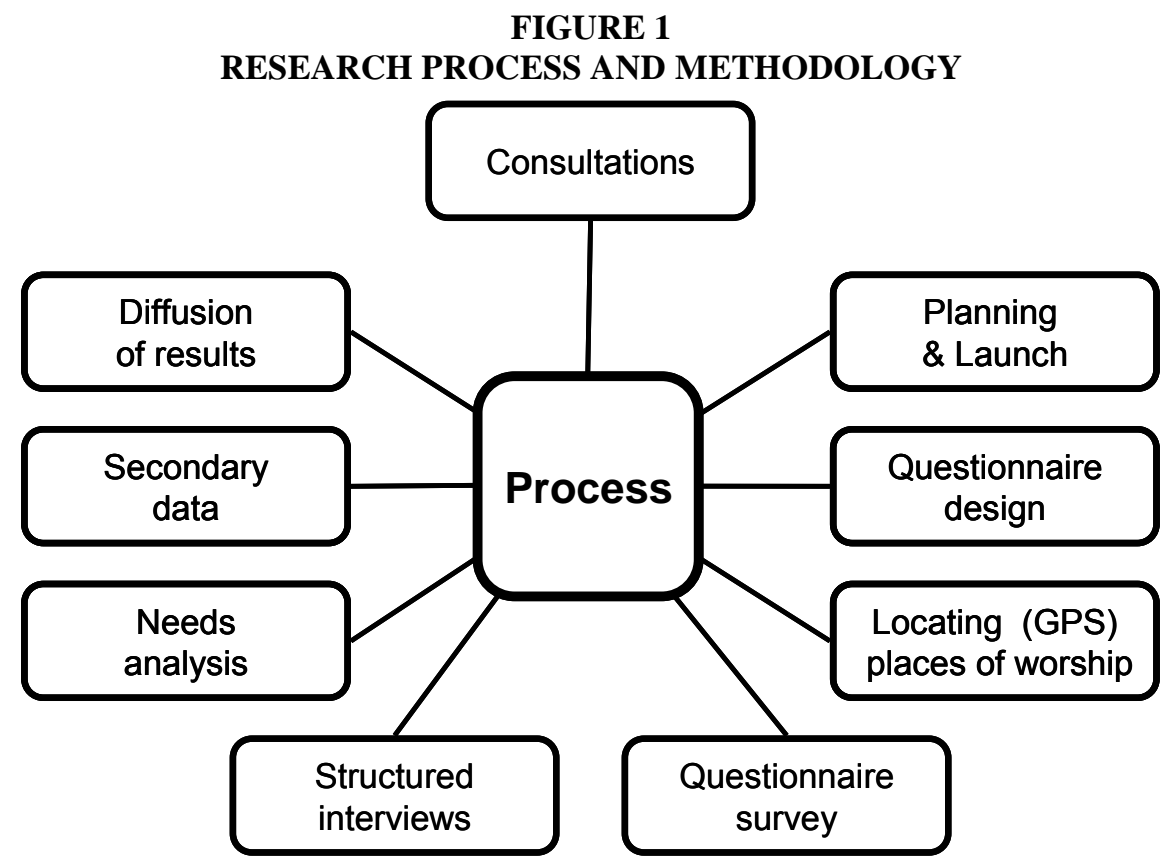

As shown in Figure 1, a variety of methodologies have been applied in the URDR-initiated research process, which accords well with the wide range of methodological applications accommodated in the PAR tradition (Babbie \& Mouton, 2001:325-328). This general overlap with PAR points out that the URDR-initiated process could also be defined as essentially multidisciplinary in nature and scope (Hendriks et al., 2004:386-387; URDR, 2004:7; 2003:10). It reflects a longer process of learning from and consultation with the other social sciences (in particular sociology and geography) whereby URDR researchers have integrated a number of established and well-known social research methodologies - both quantitative and qualitative (Babbie \& Mouton, 2001:325-327) - in its own process of applied research.

As a result, particularly novel in comparison to both conventional religious and participatory research is the way in which the URDR-initiated process has utilised GPS (Global Positioning System) and GIS (Geographical Information Systems) technology as the basis of the sequential process illustrated in Figure 1. Defined in one contribution to the subject field as a technology that "...allows a social agency to produce meaningful, attention-grabbing maps that visually show important administrative, policy, and practice issues..." (italics added) (Queralt \& Witte, 1998:456), Figure 2 shows how the combination of GPS and GIS technology likewise enabled the researchers to visually display all the places of worship in the various communities. In a very important way, the results of this applied technology support the hypothesis about the potential of FBOs in the social development sphere. In terms of ongoing theoretical and conceptual research 
undertaken within the $\mathrm{URDR}^{5}$, it also renders meaning and significance to the notion of social capital as a strategic concept when reflecting on the mobilising role of FBOs in addressing social development problems.

\section{FIGURE 2 \\ LOCATION OF THE PLACES OF WORSHIP}

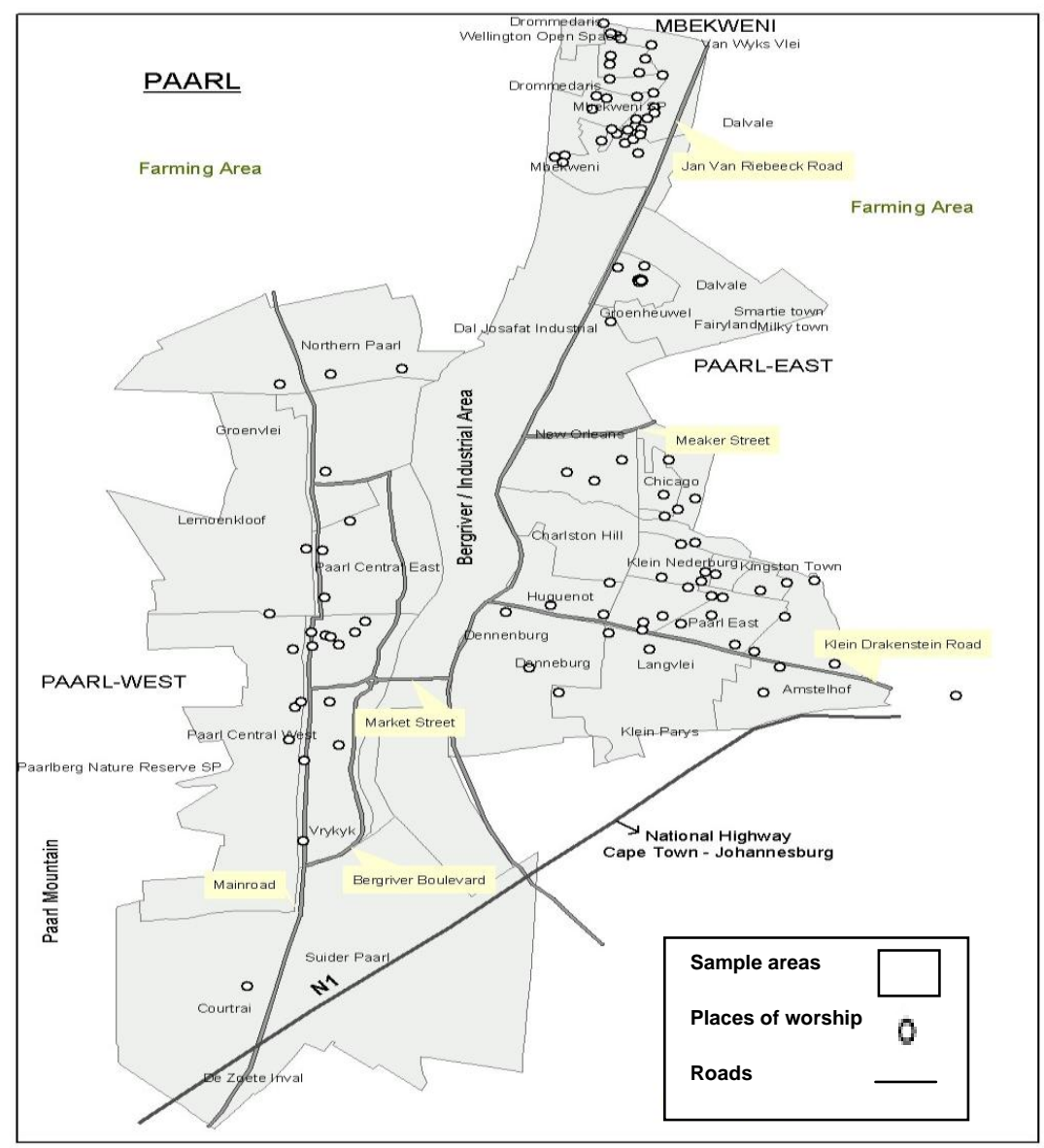

The dense and widespread location of the places of worship illustrated in Figure 2 clearly suggests that FBOs in the particular community (i.e. Paarl, but by implication also the other communities concerned, as the research results have similarly shown - URDR, 2004:27; 2003:35) could be the constituting source of networks of cooperation and trust - i.e. the social capital - through which the social problems of the immediate society may be meaningfully addressed (Hendriks et al.,

5 In addition to the PAR work the need for theoretical research or theory-building is regarded as crucial in the URDR in order to meet its objectives of empowerment and strategic innovation. In a first attempt to develop this theoretical aspect - which should also be evident from the reference to the concepts of 'social capital' and 'social development' in this article - URDR researchers have embarked on a 3-year NRF-sponsored research project (see footnote 2), 'Developing a praxis for mobilising faith-based organisations for social capital and development in the Western Cape' (URDR web page). 
2004:390-391). This illustration of social capital potential further shows how the research process could draw from the faith-based sector the sufficient number of volunteers - i.e. different groups of volunteers - to participate and act as co-executors in all aspects (or phases) of the primary research:

- The planning and launch of the primary research;

- The design of the questionnaire. At various occasions workshops were held in the different communities (Paarl, George) during which the volunteers identified the main social problems in their communities, constructed the questions for the questionnaire on the basis of such identification, and scrutinised the final version of the questionnaire. The questionnaire dealt with the issues of HIV/Aids, unemployment, sexual and/or violent crimes and substance abuse. The purpose was to establish the number of people involved in services rendered by churches and other FBOs, the number of people who receive assistance, and the perceptions of the community concerning the churches' involvement in social services (Erasmus et al., 2005:4; 2004:5-6; Erasmus \& Mans, 2005:4, 6-7; URDR, 2003:10-11);

- The location of all the places of worship. For this activity the volunteers were trained in the use of GPS technology and assisted with a GIS-produced map of their town to carry out this aspect of the research, co-ordinate their investigations, as well as conduct some additional basic fieldwork research on the places of worship that they had marked (the name, size and frequency of meetings). In turn this part of the research laid the foundation for the questionnaire survey and the structured interviews with the leadership of the churches. Based on the results of the GPS research, selected congregations were identified as strategic nodal points in the various sample areas to mobilise a new group of volunteers/fieldworkers for the questionnaire survey and to conduct the structured interviews (Erasmus et al., 2005:4-6; 2004:6-8; Erasmus \& Mans, 2005:6-7; Hendriks et al., 2004:387-388; URDR, 2003:10-12);

- The questionnaire survey. In this aspect of the research the volunteers/fieldworkers from the selected congregations distributed the questionnaires to $10 \%$ of the households in each of the sample areas (Figure 1), which through the method of spatial stratification were created by grouping together enumerator areas and sub-areas with the same demographic profile. An overall return rate of respectively $72.9 \%$ and $65 \%$ of the questionnaires was achieved in the communities of Paarl and George, whilst a number of congregations in the sub-areas managed a 100\% return rate (Erasmus et al., 2005:5-6; 2004:6-7; Hendriks et al., 2004:387-388; URDR, 2003:12-13);

- The structured interviews with congregational leadership. The purpose of this activity was to complement the information gathered through the survey by interviewing (through a separate questionnaire) a sample of leaders who represented both the demographics and denominational spread of the communities. More specifically, the aim was to explore the partnerships within which churches in the communities operate and to obtain information about their existing social ministries (Erasmus et al., 2005:6; 2004:7-8; Hendriks et al., 2004:388, 392-393; URDR, 2003:14);

- The needs analysis. This aspect derived from the felt need to complement the research results with more qualitative data. The purpose of the needs analysis was to prioritise the social development needs specific to some of the poorest sections of the different communities by using the Priority Index (P-Index) research technique, i.e. a methodology that is strongly based on the principles of PAR and directly involves individuals and target groups in the communities in prioritising the communities' needs. Secondly, the purpose was to draw 
community profiles (C-Indexes) of every selected community by using the data of the P-index. Through this second element the degree of satisfaction of particular basic and social needs in the communities was measured (Schutte, 2000; Erasmus et al., 2005:6-7; 2004:8-9; URDR, 2004:8-9, 33-38; 2003:18-22).

Lastly Figure 1 indicates that, in addition to the primary research components, secondary data collected from various sources - the SA Police Service, local and regional health services, Census 1996 and 2001 - were analysed and integrated as part of the research results. This aspect was added to the research process as it was recognised by some of the volunteers who participated in the questionnaire design workshops that other sources of data on the social problems that they identified (HIV/Aids, unemployment, and sexual and/or violent crimes) were already available. These sources, therefore, were seen by both the URDR researchers and research participants as very valuable in shedding further light on the nature and extent of the identified problems (Erasmus et al., 2005:4; 2004:9; Hendriks et al., 2004:388; URDR, 2004:38-40; 2003:15). Furthermore, it added a dimension that falls well within the recognised parameters of PAR allowing quantitative data-collection methods and secondary data to be included in the research (Babbie \& Mouton, 2001:326-327).

\section{DIFFUSION OF THE RESEARCH RESULTS}

In accordance with one of the fundamental imperatives of PAR that the research results should be returned to the participants (Babbie \& Mouton, 2001:329; Prozesky and Mouton, 2001:542), the URDR researchers took a great deal of trouble to communicate the results of the research in an interactive way to members of the respective communities, including those who participated directly in the research. In this regard two of the most salient aspects of the research process once again surfaced prominently.

Firstly, in the process of diffusion local congregations played an invaluable role by acting as the venues where the research results could be communicated to members of the community and the faith-based sector in a series of feedback sessions. Furthermore, having access to the infrastructure of the local churches ensured that the community at the grassroots level (Babbie \& Mouton, 2001:329) could be reached sufficiently. These venues also appeared attractive to members of the faith-based sector and their leaders, who as a group turned out to be the most committed to the ongoing process both in terms of their attendance of and/or participation in the feedback sessions and their co-organisation of the events (Erasmus et al., 2005:7-8; 2004:9-10; URDR, 2004:40; URDR, 2003:23).

Secondly, in the process of diffusion GIS technology also played a key role. Following the earlier reference to the significance of this technology and its strategic place in the research process, the value of GIS was further exploited in the diffusion process. The secondary data (from the various sources) and primary data (from the questionnaire and GPS) were put into a geodatabase and aggregated to the sample areas that were created earlier in the research process. Combining this information in such a way enabled the researchers to present a digital or hardcopy visual display of the different layers of data. Each layer represents one of the variables in the geodataset. In the layers the variation in the data for the specific variable is portrayed (Erasmus et al., 2005:8; 2004:9-10; Erasmus \& Mans, 2005:8; Hendriks et al., 2004:388-389; URDR, 2004:9).

For instance, Figure 3 is an example of a map showing one layer of information from the geodataset. On the map one can see the variation in the occurrence of sexual and violent crimes against women and children in one of the researched town regions (i.e. Paarl). In this figure the darker areas indicate a higher intensity of such crimes. Thus the map shows that the areas north 
and east (the township of Mbekweni and the area traditionally called Paarl-East) experienced the highest rate of sexual and/or violent crimes in the region in one particular year (i.e. 2001) (Erasmus \& Mans, 2005:9).

\section{FIGURE 3}

\section{CASES OF SEXUAL AND VIOLENT CRIMES AGAINST WOMEN AND CHILDREN}

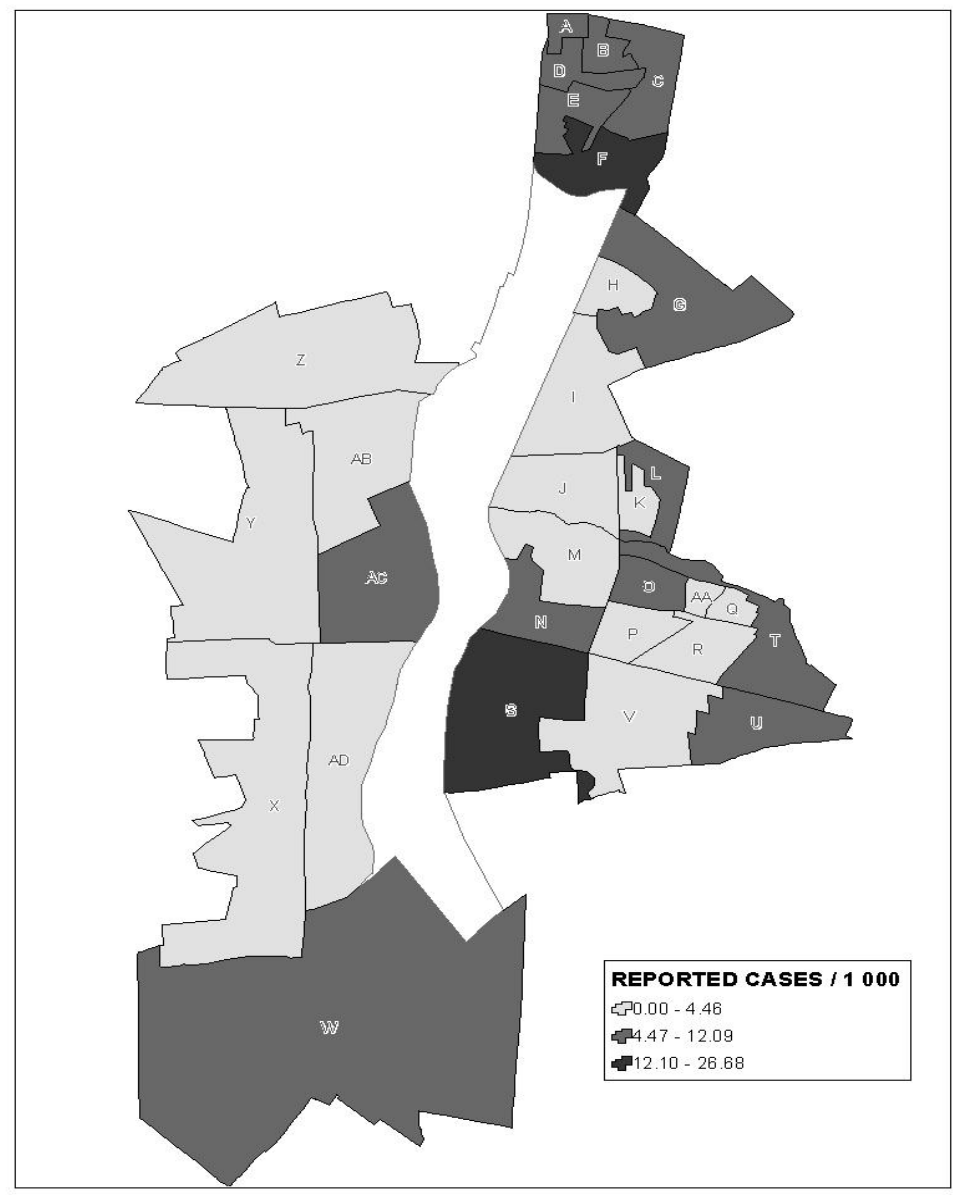

Yet the value of GIS technology has become further evident in that it has made it possible for the researchers and participants to identify more complex connections and relationships on the basis of the different layers of information (Hendriks et al., 2004:389). For example, relating the information in Figure 3 to subsequent layers of information on the specific problem also visually illustrated by maps revealed that those areas with the highest prevalence of sexual and violent crime generally also scored the highest with regard to (i) the degree to which people are involved in assisting crime victims, and (ii) the degree of assistance that victims had received (Erasmus \& Mans, 2005:8-9, 21-22).

Based on all the layers of information it could therefore not only be determined and illustrated in which areas the need for assistance remains high (Erasmus \& Mans, 2005:9, 23). The information 
also revealed a rather general trend, namely that members of the community seemed more involved in areas where people are more exposed to the problem than in areas where the problem is less prevalent (Erasmus \& Mans, 2005:11). This furthermore opened up an important perspective on the role of the faith-based sector. The various layers of information derived from the questionnaire survey (see the three aims of the questionnaire indicated above), as well as the geographic location of all the places of worship executed earlier (Figure 2), strongly suggested that members of the local churches played an important role in assisting the victims of sexual and/or violent crimes in the community. However, this appeared to be a role less played by the organisational arm of the churches than by members in their personal capacity as well as in their involvement with other FBOs (Erasmus \& Mans, 2005:11). At the same time, the information newly revealed where the local faith community could play a strategic role on the basis of the existing need for assistance (Erasmus \& Mans, 2005:23).

It should be mentioned, finally, that the GIS technology was not an appropriate instrument to deal effectively with the results produced by the needs analysis and the structured interviews. Yet, as an additional complementary aspect to the research, the needs analysis in particular proved to be a valuable medium to further enhance an awareness of what people themselves experienced and perceived to be the actual needs (Schutte, 2000:7) of their communities. It highlighted the fact that from the experience of the respective communities a broader social development strategy would be needed that, besides the issues raised in the questionnaire, should also address a range of other social welfare needs (amongst others, housing, income, recreation, safety, health care, sanitation and education) (URDR, 2004:33-38; URDR, 2003:18-22).

\section{CONCLUSION: THE ONGOING CHALLENGE OF CONSCIENTISATION AND EMPOWERMENT}

This article - in the context of current institutionalised theological and religious research in South Africa - has recorded a unique initiative by the Unit for Religion and Development Research (URDR) to empower the faith-based sector in selected communities in the Western Cape towards achieving sustainable social development activity and outcomes through a participatory action research (PAR) process.

Looking back at the whole initiative so far, it can be concluded that it has been particularly successful in a first round of conscientisation, i.e. in raising the general awareness in the particular communities and especially amongst people of faith about the nature and extent of the major social problems in the communities as well as the most pertinent social needs identified by members of the communities themselves (Babbie \& Mouton, 2001:322-323; Prozesky \& Mouton, 2001:547-548). In this regard it has also been indicated how the technology of GIS has been used to good effect in presenting the communities with a visual orientation of the problem, in highlighting to them where people were suffering most under the identified problems, where members of the community were already involved in addressing the problems and to what degree, and where the need for proactive involvement on the part of the community remained high. No less important, through this technology people's awareness could be raised with regard to the potential of the local faith-based sector as a strategic actor in addressing the problems in the various communities.

Furthermore, it could also be asserted that a certain degree of empowerment has been achieved through the whole endeavour. As the description of the research process has highlighted, members of the respective communities were active participants in all aspects of the primary research component. As such they were exposed to a number of different research methodologies through which their understanding of social research and their capacity to conduct their own research, were 
definitely strengthened. In accordance with one of the basic objectives of PAR, one could look back at a process that has managed to popularise research to a significant degree (Babbie \& Mouton, 2001:324; Prozesky \& Mouton, 2001:549). Participants were familiarised with the value and use of highly sophisticated research technology (GIS and GPS), as well as introduced to still simpler forms of conventional social research methodologies (the questionnaire and needs analysis) that have enhanced the participatory quality of the research.

However, whilst important outcomes of a PAR process have been achieved, it should be concluded in the final analysis that the URDR initiative has not yet led to the kind of independent and transformative action that is identified as the fundamental outcome of PAR. Indeed, judged by the self-critical perspective that has informed this article from the start, as well as by the claim to the latter kind of action made in the theoretical literature (Prozesky \& Mouton, 2001:546-547; Rahman, 1993), the challenge before the URDR initiative remains considerable.

Hence it should be evident by now that this article has based its argument on the basic premise that the research methodology of PAR is a most useful and appropriate medium in the promotion of social development. Conscientising communities and particular strategic actors in those communities about pertinent social problems and mobilising them towards processes whereby they would solve those problems in a sustainable manner through their own capacities and strengths clearly seem to overlap significantly with the set objectives of social development that have also been adopted as the paradigm for social welfare delivery in post-apartheid South Africa (Coughlan \& Collins, 2001; Department of Social Development, 2002; Department of Welfare and Population Development, 1997; Midgley, 2001; 1999; 1998; Patel, 2003; Schurink, 1998; Sewpaul, 1997). At the same time, it is within this shared framework that the ongoing task to conscientise and empower the participants in the PAR process in a more informed way in terms of the ideological and paradigmatic challenges of social development is recognised.

Concerning the faith-based sector in particular, the starting-point of the envisaged ongoing initiative of conscientisation and empowerment will be to reflect with a broad representation from this sector in the respective communities on how the social development paradigm challenges their conventional welfare practices and how their social actions would impact differently on the identified problems in their communities, if informed by and based on the social development paradigm. Furthermore, from such reflection should follow a concerted effort by the FBOs in those communities to implement a broad diversity of social development strategies and programmes (Midgley, 1999), whose progress and effectiveness should be evaluated in turn in subsequent rounds or phases of PAR in which members from the faith-based sector and URDR researchers both participate (Babbie \& Mouton, 2001:330). The following quote captures the kind of 'reflection and action' process in mind here particularly well:

"Participatory action research starts small and develops through the self-reflective spiral: a spiral of cycles of planning, acting (implementing plans), observing (systematically), reflecting and then re-planning, further implementation, observing and reflecting... the collective reflects on observations made about action taken so far and uses this collective activity to inform decisions about future action steps of the group and of individuals." (McTaggart in Babbie \& Mouton, 2001:330)

In conclusion, it seems fitting at this point to again recall the critical statement early in this article about the shortcomings of the URDR initiative to date as an exponent of the 'Southern' tradition of PAR. Indeed, one may envisage that by making the issue of social development its serious concern in the way forward, the URDR initiative could go a long way towards addressing the current shortcomings. As is becoming increasingly clear from the URDR researchers' own 
exploration into social development theory ${ }^{6}$, the challenge ahead is nothing less than a radical one. Their striving to address social problems and needs in a developmental way will furthermore mean that the partnership of URDR researchers and local FBOs will become more activist in their approach by newly challenging the prevailing inequalities, power relations and structures of exclusion in the communities where they aspire to make a difference (Cox, 2001:46-47; Cox, 1998; Sewpaul, 1997:4-7). In a language well known to critical theological and religious actors, it points to a new preferential option for the poor and oppressed and a preoccupation with the cause of social justice (Swart, 2004; Department of Social Development, 2002).

\section{BIBLIOGRAPHY}

BABBIE, E. \& MOUTON, J. 2001. The practice of social research. Cape Town: Oxford University Press.

CENSUS 2001. Unpublished data on religion obtained from Stats SA. URDR.

CENSUS 1996. Unpublished data on religion obtained from Stats SA. URDR.

COUGHLAN, F.J. \& COLLINS, K.J. 2001. Participatory developmental research: a working model. International Social Work, 44(4):505-518.

COX, D. 1998. Towards people-centred development: The social development agenda and social work education. The Indian Journal of Social Work Education, 59(1):513-530.

COX, E.O. 2001. Community practice issues in the $21^{\text {st }}$ century: Questions and challenges for empowerment-oriented practitioners. Journal of Community Practice, 9(1):37-55.

DEPARTMENT OF WELFARE AND POPULATION DEVELOPMENT 1997. White Paper for Social Welfare. Pretoria: Department of Welfare.

DEPARTMENT OF SOCIAL DEVELOPMENT 2002. Strategic Plan 2002/2003 to 2004/2005. Pretoria: Department of Social Development.

ERASMUS, J.C. \& MANS, G.G. 2005. Churches as service providers for victims of sexual and/or violent crimes: A case study from the Paarl community. Acta Criminologica, 18(1):140-163.

ERASMUS, J.C., HENDRIKS, H.J. \& MANS, G.G. 2005. Religious research as kingpin in the fight against poverty and Aids in the Western Cape, South Africa. Paper submitted for publication in Journal for Empirical Theology.

ERASMUS, J.C., HENDRIKS, H.J. \& MANS, G.G. 2004. Research Report: Church and Community Research Project [on line]. Rev. 20 October 2004. Available:

http://academic.sun.ac.za/theology/egdn/RESEACH\%20METHODOLOGY_PAARL\&GEORGE.pdf.

FROISE, M. \& HENDRIKS, H.J. 1999. South African Christian Handbook 1999-2000. Welkom: Christian Info.

HENDRIKS, H.J. \& ERASMUS, J.C. 2003. Religious affiliation in South Africa early in the new millennium: Markinor's World Values Survey. Journal of Theology for Southern Africa, 117(Nov):80-96.

HENDRIKS, H.J., ERASMUS, J.C. \& MANS, G.G. 2004. Congregations as providers of social service and HIV/AIDS care. Dutch Reformed Theological Journal (NGTT), 45(2) Supplementum:380-402.

6 The reference is here likewise to the research project mentioned in the previous footnote. 
KOEGELENBERG, R.A. 2001. Social development partnerships between religious communities and the state: Perspectives from the National Religious Association for Social Development (NRASD). Journal of Theology for Southern Africa, 110:97-109.

LOUW, L. \& KOEGELENBERG, R.A. 2003. Building a new South Africa: The building of a caring, democratic and equitable society through partnerships between the state and the National Religious Leader's Forum (NRLF). Position paper prepared for the NRLF meeting with President Thabo Mbeki, 29-30 April 2003. A perspective from the National Religious Association for Social Development (NRASD) [on line]. Rev. 30 September 2003. Available: http://sarpn.org.za/documents/d0000557/index.php.

MIDGLEY, J. 2001. South Africa: The challenge of social development. International Journal of Social Welfare, 10(4):267-275.

MIDGLEY, J. 1999. Growth, redistribution, and welfare: Toward social investment. Social Service Review, 73(1):3-21.

MIDGLEY, J. 1998. Social development and social welfare: South Africa in an international context. Social Work/Maatskaplike Werk, 34(1):90-98.

MINISTRY OF SOCIAL DEVELOPMENT 2004a. Minister Skweyiya and religious leaders agree on closer cooperation in tackling poverty, unemployment and HIV/AIDS. Media release, 20 July 2004. Available: www.socdev.gov.za.

MINISTRY OF SOCIAL DEVELOPMENT 2004b. Address by Dr Zola Skweyiya, Minister of Social Development, to the consultation on state-religious sector development cooperation, Bishopscourt, 20 July 2004. Media release, 20 July 2004. Available: www.socdev.gov.za.

PROZESKY, H. \& MOUTON, J. 2001. The participatory research paradigm. In: COETZEE, J.K., GRAAFF, J., HENDRICKS, F. \& WOOD, G. (eds), Development: Theory, policy, and practice. Cape Town: Oxford University Press Southern Africa.

PATEL, L. 2003. Social development in a society in transition. Social Development Issues 25(1\&2):150-161.

QUERALT, M. \& WITTE, A.D. 1998. A map for you? Geographical information systems in the social services. Social Work, 43(5):455-469.

RAHMAN, A. 1993. People's self-development. Perspectives on participatory action research: A journey through experience. London: Zed Books.

SCHURINK, E.M. 1998. Participatory action research as a tool for sustainable social development and reconstruction. In: DE VOS, A.S. (ed) Research at grass roots: A primer for the caring professions. Pretoria: Van Schaik.

SCHUTTE, D. 2000. People first: Determining priorities for community development. Parow: Ebony Books.

SEWPAUL, V. 1997. The RDP: Implications for social work practice and social welfare policy development in South Africa. Social Work/Maatskaplike Werk, 33(1):1-9.

SWART, I. 2004. Networks and partnerships for social justice? Critical reflection on the pragmatic turn in the religious social development debate in South Africa. Paper presented at the $31^{\text {st }}$ International Conference of the International Council on Social Welfare (ICSW) in Kuala Lumpur, Malaysia, 16-20 August 2004. 
URDR 2003. George Aids Forum Research Report [on line]. Rev. 20 October 2004. Available: http://academic.sun.ac.za/theology/egdn/GeorgeAidsForumReport2003.PDF.

URDR 2004. Transformation Research Project: Paarl/Wellington. Stellenbosch: URDR.

URDR WEB PAGE. http://academic.sun.ac.za/theology/urdr.htm.

WORLD VALUES SURVEY 2000. Unpublished data obtained from Markinor. URDR.

Dr Ignatius Swart, Senior Lecturer, Department of Practical Theology and Missiology, University of Stellenbosch, Stellenbosch, South Africa. 